\title{
Los enigmas de Antología griega: presentación y traducción
}

\author{
Mariana Gardella ${ }^{1}$
}

I offer here a translation into Spanish of the riddles from the fourteenth book of the Greek Anthology. The translation is accompanied by a brief description of the content of this book and the main devices used for the composition of riddles (metaphor, metonymy, ambiguity, antithesis, and personification). At the end, there is a list of the responses to the riddles.

\section{Presentación}

Uno de los desafíos que enfrentan los llamados riddle studies es definir qué es un enigma. Sin embargo, en algunos de los estudios realizados en este campo, se ha defendido que no es posible formular una definición universal de este concepto. ${ }^{2}$ Los enigmas son una expresión del folklore de los pueblos. Su forma, contenido y función varía de una cultura a otra. Por esta razón, toda definición estará condicionada por el conjunto particular de enigmas que se tome como referencia.

\footnotetext{
${ }^{1}$ He realizado este trabajo gracias al apoyo del Programa de Becas Posdoctorales de la Universidad Nacional Autónoma de México, donde me desempeño desde septiembre de 2019 como Becaria Posdoctoral del Instituto de Investigaciones Filosóficas. Agradezco al Dr. Ricardo Salles, quien supervisa mi investigación, por las valiosas observaciones formuladas a mi trabajo.

${ }^{2}$ Al respecto, la posición más destacada es la de Köngäs Maranda, Elli (1969). "Structure des énigmes". L'Homme 9 (3), p. 7: "J'établis qu'une définition théorique de l'énigme n'est pas nécessaire à l'identification du genre [...]. En fait, une définition a priori serait théoriquement mal fondée, puisque ce que nous voulons étudier est une 'classe' de faits établie par les participants de la culture”. Una opinión contraria sostiene Kaivola-Bregenhøj, Annikki (2001). Riddles. Perspectives on the Use, Function and Change in a Folklore Genre. Helsinki: Studia Fennica Folkloristica, p. 47: "A definition of the riddle may be sought for a number of research purposes and needs, such as analysis of the use of metaphor, classification of the content and stylistic devices of a riddle, the structuralistic identification of folkloristic genres, or the description of a riddle in a performing context".
} 
En textos de la tradición filosófica griega, encontramos las definiciones más

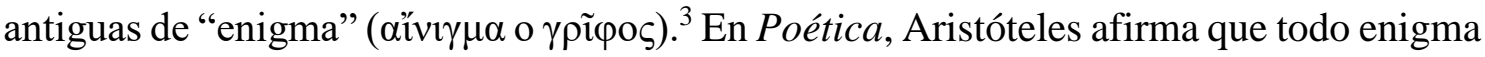
consiste en "hacer combinaciones imposibles para referir a cosas que son" y que sólo es posible formular este tipo de combinaciones a través del uso excesivo de metáforas. ${ }^{4}$ En

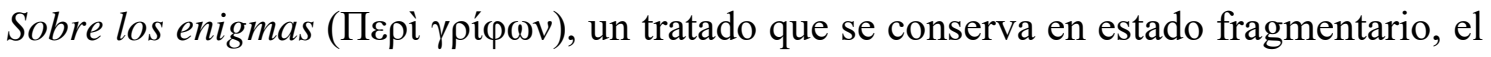
peripatético Clearco de Solos define el enigma como un problema entretenido que motiva el desarrollo de una investigación. ${ }^{5}$ Además, presenta una clasificación que comprende no sólo los enigmas que, siguiendo la definición de Aristóteles, refieren a cosas que son

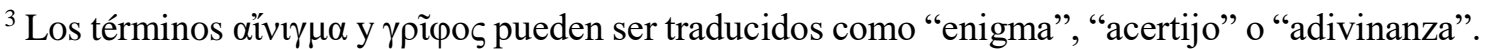
Para un panorama general sobre los enigmas en Grecia antigua, $c f$. Colli, Giorgio (1977). La sapienza greca. Vol. I: Dioniso, Apollo, Eleusi, Orfeo, Museo, Iperborei, Enigma. Milano: Adelphi; Pucci, Pietro (1996). Enigma, segreto, oracolo. Pisa-Roma: Istituti Editoriali e Poligrafici Internazionali; Berra, Aurélien (2008). Théorie et pratique de l'énigme en Grèce ancienne. Paris: École des Hautes Études en Sciences Sociales; y Beta, Simone (2016). Il labirinto della parola. Enigmi, oracoli e sogni nella cultura antica. Torino: Einaudi.
}

${ }^{4}$ Aristóteles, Po. XXII 1458a23-29: "Si alguien compusiera todas [sc. las expresiones poéticas] de este modo [sc. utilizando términos inusuales], resultará un enigma o un barbarismo. En efecto, si [la expresión poética se compone sólo] de metáforas, [resulta] un enigma, si de nombres extranjeros, un barbarismo. Pues la forma del enigma es esta: hacer combinaciones imposibles para referir a cosas que son. Ciertamente, no se puede hacer esto por medio de la combinación de

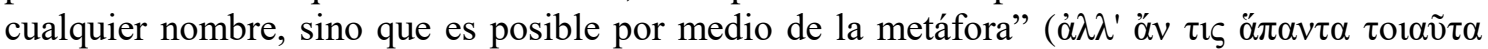

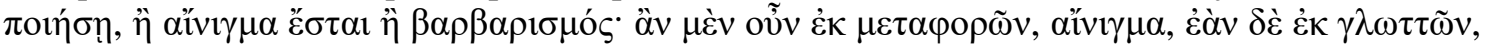

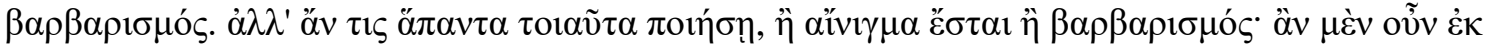

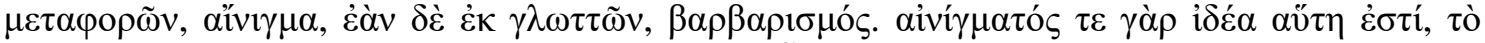

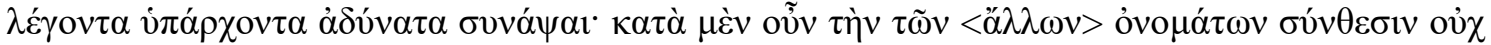

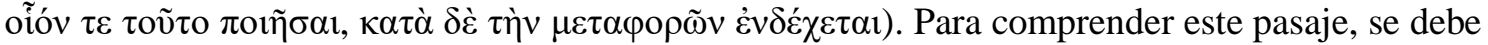
recordar que, de acuerdo con la opinión de Aristóteles, la $\lambda \dot{\varepsilon} \xi 1 \zeta$ poética debe ser clara, pero sin caer en lugares comunes. La claridad se logra a través del empleo de los nombres propios ( $\dot{\eta} \dot{\varepsilon} \kappa$

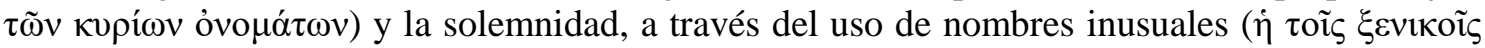
$\kappa \varepsilon \chi \rho \eta \mu \varepsilon ́ v \eta)$. En este último grupo, se incluyen los términos extranjeros o dialectales ( $\gamma \lambda \tilde{\omega} \tau \tau \alpha \nu)$,

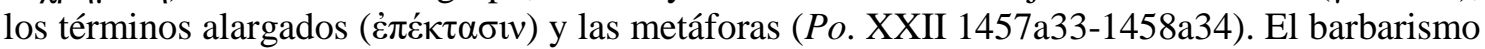
equivale al solecismo ( $\sigma 0 \lambda$ oıkı $\sigma \mu$ ó $)$ y consiste en hablar griego incorrectamente (SE III 165b2021, $R h$. III 1407a19-b25). Aristóteles también se refiere al enigma en Mete. I 347a3-8 y Rh. II 1394b33-1395a2, III 1405a34-1405b5, 1412a24-26.

${ }^{5}$ Clearco, fr. 86 Wehrli (= Ateneo X 448c): "Clearco lo define de este modo: un enigma es un problema entretenido que exige descubrir la solución a través de una investigación realizada por medio de la inteligencia, y que ha sido arrojado con la intención de otorgar un premio o un

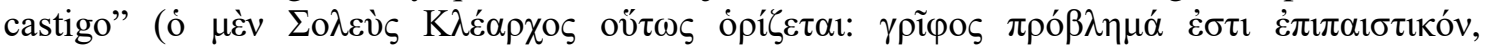

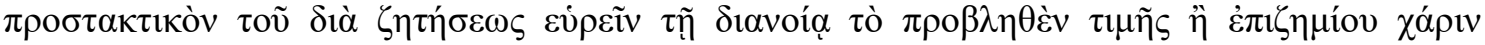

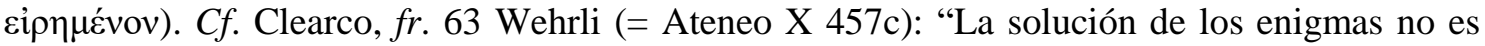
ajena a la filosofía y con ellos los antiguos realizaban una demostración de su educación" ( $\tau \tilde{\omega} v$

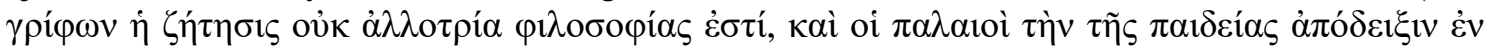

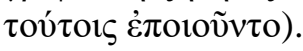


a través de descripciones extrañas o imposibles, sino también aquellos que resultan de juegos con palabras. ${ }^{6}$

$\mathrm{Si}$, como he sugerido, toda definición de "enigma" guarda una estrecha relación con el conjunto particular de enigmas que se intenta definir, entonces, para comprender mejor las definiciones de Aristóteles y Clearco, es preciso conocer cuáles eran los enigmas que tomaban como referencia. Sin embargo, Aristóteles y Clearco citan pocos ejemplos de enigmas. En el corpus aristotelicum, encontramos sólo dos. Por una parte, el enigma de la ventosa de Cleobulina de Lindos, citado dos veces, en Poética y Retórica:

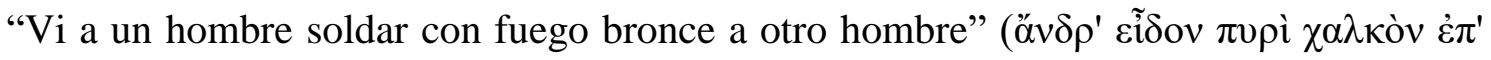

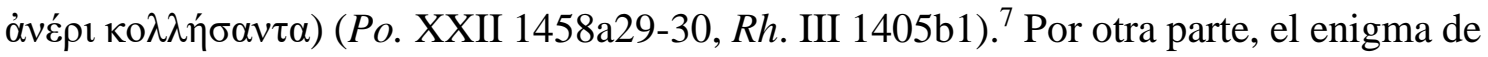

\footnotetext{
${ }^{6}$ Clearco, fr. 86 Wehrli (= Ateneo X 448c-e): "En Sobre los enigmas, el mismo Clearco dice que existen siete clases de enigmas. 'A partir de la letra', por ejemplo, cuando tenemos que decir palabras [que comienzan] con alfa, como un nombre de pez o planta. Lo mismo ocurre cada vez que alguien solicita que [los nombres] tengan o no tengan alguna de las letras, como los enigmas llamados 'asigmáticos'. De ahí que Píndaro también haya compuesto una oda contra la sigma, como si se tratara de cierto enigma arrojado en la composición lírica. Se dice que existen enigmas 'a partir de la sílaba', cuando tenemos que decir cualquier verso que esté encabezado por - $b a$, por ejemplo basileús; o que finalice en -nax, por ejemplo Kalliánax; o que empiece con 'león', como Leónidas; o que por el contrario lo tenga al final, como Trasileón. Y hay enigmas 'a partir del nombre', por ejemplo, cuando tenemos que decir nombres simples o compuestos de dos sílabas cuya forma se muestre elevada o baja; o nombres que no tengan relación con dioses, como Cleónimo, o que sí la tengan, como Dionisio —en este caso, pueden estar formados a partir [del nombre] de un dios o de muchos, como Hermafrodito-; o que comiencen por Zeus, como Diocles; o con Hermes, como Hermodoro; o que finalicen, si se puede, en -nikos. Quienes no

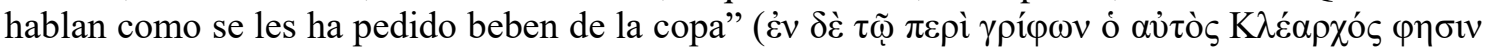

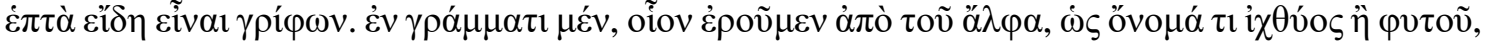

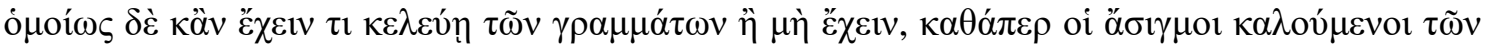

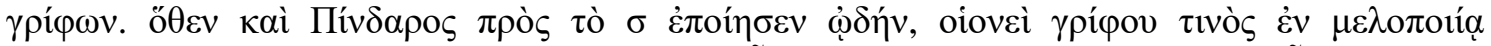

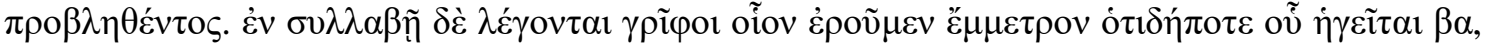

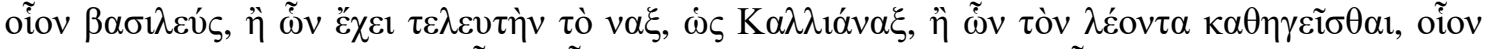

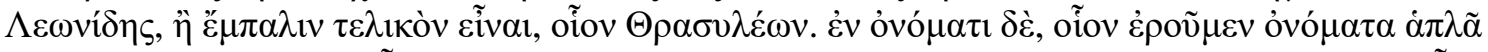

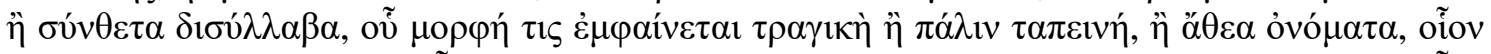

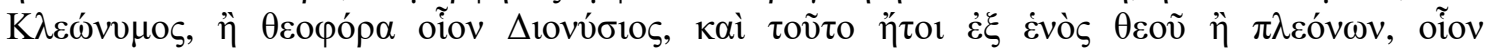

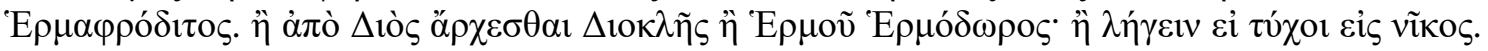

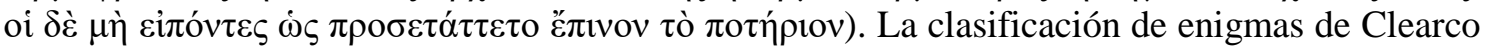
transmitida por Ateneo está incompleta. Para un intento de reconstrucción de los siete tipos de enigma, cf. Wehrli, Fritz (1948). Die Schule des Aristoteles. Texte und Kommentar. Heft III:

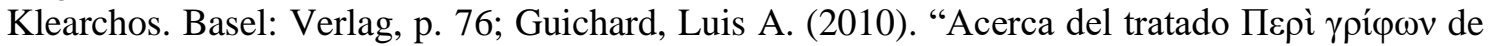
Clearco de Solos". En Francisco Cortés Gabaudán y Julián V. Méndez Dosuna (eds), Dic mihi, Musa, virum. Homenaje al Profesor Antonio López Eire. Salamanca: Ediciones Universidad de Salamanca, pp. 287-290; y Luz, Christine (2010). Technopaignia. Formspiele in der griechischen Dichtung. Leiden-Boston: Brill, pp. 141-146.

${ }^{7}$ Para otras versiones del mismo enigma, cf. Plutarco, Symp. 154b12; Ateneo, X 452b10; Demetrio, De eloc. 102; Siriano, in Hermog. 36.12-14 y Juan de Sicilia, in Hermog. 199.30-200.2. La solución del enigma es la aplicación de las ventosas, un procedimiento médico empleado para recuperar el balance de los humores. Las ventosas se calentaban y adherían al cuerpo por medio del vacío generado por el calor para aliviar la tensión muscular y mejorar la circulación $(c f$.
} 
los piojos que unos niños le propusieron a Homero y que ha sido transmitido en Sobre los

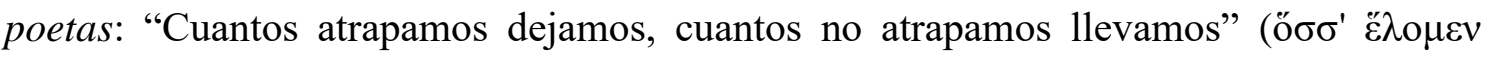

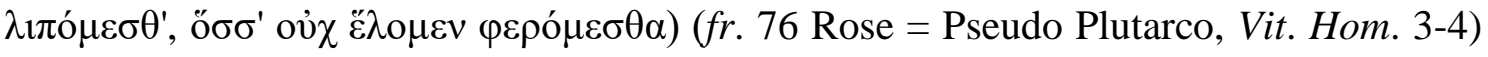
( $c f$. Heráclito DK 22 B 56 = Hipólito, Haer. IX 9.5). De las siete clases de enigmas que distinguió Clearco, sólo tenemos ejemplos de las primeras tres porque son las únicas que describe Ateneo en su Banquete de los sabios cuando cita algunos pasajes del tratado del peripatético: decir palabras que empiezan con alfa o que no tienen sigma (enigmas a partir de la letra); decir versos que comienzan con - ba o que finalizan en -nax (enigmas a partir de la sílaba); y decir nombres que tienen relación con los dioses, como Dionisio, Hermafrodito, Diocles o Hermodoro (enigmas a partir del nombre). Sabemos además que, en su tratado, Clearco mencionó el enigma del eunuco al que también hace referencia Platón en República: “A un pájaro no pájaro que estaba posado en un tronco no tronco,

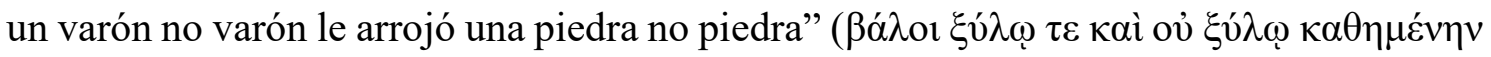

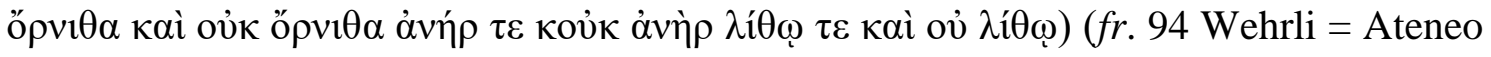
$\mathrm{X} 452 \mathrm{c}){ }^{8}$

Los escasos ejemplos citados por Aristóteles y Clearco pueden enriquecerse con aquellos que se encuentran en el libro décimo de Banquete de los sabios de Ateneo ( $c f$. 448b-459c) y en el libro decimocuarto de Antología griega (= AG). En esta última obra, se transmite la colección más extensa de enigmas de la tradición griega antigua. Aunque estos fueron editados - y probablemente compuestos - con posterioridad a la muerte de Aristóteles y Clearco, o bien reproducen enigmas clásicos, o bien están inspirados en ellos.

Aquí ofrezco una traducción completa del griego al castellano de los enigmas transmitidos en Antología griega. He tomado como referencia la edición del texto griego hecha por Hermann Beckby. ${ }^{9}$ Con respecto al criterio de traducción, he intentado recrear el ritmo propio de los enunciados enigmáticos que son, como afirma Clearco, problemas divertidos. Por esta razón, en algunos casos, he sacrificado la estricta literalidad en favor de expresiones y giros que permiten recuperar la gracia y el colorido de los acertijos. En

Hipócrates, $V M$ 22). El enigma establece una analogía entre el trabajo de un soldador que por medio del fuego suelda bronce con el del médico que aplica ventosas calientes del mismo material sobre el cuerpo de sus pacientes. Para una presentación general de Cleobulina y sus enigmas, $c f$. Matelli, Elisabetta (1997). "Sulle tracce di Cleobulina". Aevum 71 (1), pp. 11-61 y Gardella, Mariana y Juliá, Victoria (2018). El enigma de Cleobulina. Buenos Aires: Teseo.

${ }^{8} C f$. Platón, $R$. V 479c1-5.

${ }^{9}$ Beckby, Hermann (1958). Anthologia Graeca. Bd. 4: Buch XII-XVI. München: Heimeran. 
general, he respetado la disposición y el orden de los versos, pero no así el orden de las palabras de cada verso. La traducción viene precedida de dos secciones: en la primera, describo brevemente las principales características del libro decimocuarto de Antología griega (1. 1); en la segunda, distingo los principales recursos empleados en la formulación de los enigmas, lo que facilitará su lectura y comprensión (1.2). Al final de la traducción (2. 2), se hallarán las respuestas de los acertijos (2. 2).

\section{1. El libro decimocuarto de Antología griega}

Antología griega reúne una gran cantidad de epigramas compuestos en diversas épocas y editados previamente en otras antologías como Corona ( $\Sigma \tau \varepsilon \dot{\varphi} \varphi \alpha \nu \circ)$ de Meleagro de Gádara (siglo I a. e. c.), Corona de Filipo de Tesalónica (siglo I a. e. c.), la colección

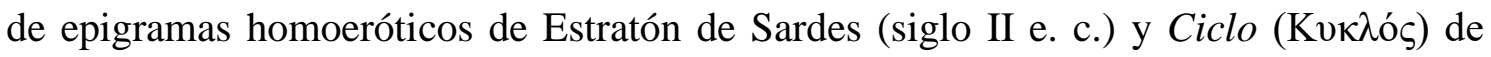
Agatías Escolástico (siglo VI e. c.). ${ }^{10}$ Tal como la conocemos hoy, Antología griega ha sido el resultado de la edición conjunta de dos antologías: Antología palatina, editada bajo la dirección de Constantino de Céfalas entre 930 y 980 e. c., y ampliada por un erudito bizantino anónimo; y Antología planudea, compuesta por Máximo Planudes circa 1301 e. c. ${ }^{11}$

Se cree que los libros XIII-XV fueron agregados con posterioridad a la edición de Céfalas, dado que, desde el punto de vista de la forma y el contenido, son diferentes de

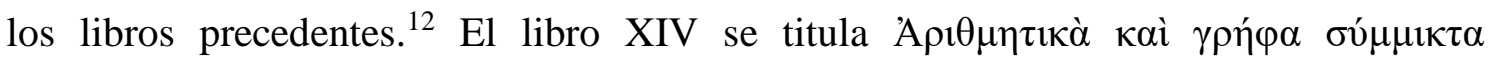
("Problemas matemáticos y enigmas diversos"). Por $\gamma \rho \eta ́ \varphi \alpha$ se debe comprender $\gamma \rho \tilde{i} \varphi$ c. $^{13}$ El título no refleja completamente el contenido del libro, ya que en él se incluyen no sólo problemas matemáticos y enigmas, sino también oráculos. El adjetivo $\sigma u ́ \mu \mu \iota \kappa \tau \alpha$ podría

${ }^{10}$ Cf. Berra 2008, p. 631 y Cameron, Alan (1993). The Greek Anthology. From Meleager to Planudes. Oxford: Clarendon Press, pp. 19-77.

${ }^{11}$ Cf. Cameron 1993, pp. 97-159. La primera edición impresa de Antología griega fue hecha en 1494 por Giovanni Lascaris. Hasta el siglo XVIII, todas las ediciones de esta obra se hicieron exclusivamente a partir de Antología planudea. Las ediciones de Antología palatina publicadas recién entre fines del siglo XVIII y principios del XIX permitieron incorporar este texto a Antología griega. Cf. Bing, Peter y Bruss, Jon S. (2007). "Preface". En Peter Bing y Jon S. Bruss (eds), Brill's Companion to Hellenistic Epigram. Down to Philip. Leiden-Boston: Brill, pp. 2026.

${ }^{12}$ Cameron 1993, p. 135.

${ }^{13}$ El iotacismo es evidente. De acuerdo con la hipótesis de Berra 2008, p. 247, $\gamma \rho \eta ́ \varphi \alpha$ sería la forma neutra plural de un adjetivo sustantivado derivado de $\gamma \rho \tilde{i} \varphi o t$. 
sugerir que los oráculos son considerados un tipo particular de enigma y que, por esta razón, no son mencionados en el título como una clase aparte. ${ }^{14}$ Esto no sería extraño, ya que muchas respuestas oraculares tenían la apariencia de acertijos, debido a que, para su formulación, se utilizaban recursos retóricos similares a los que se empleaban para la composición de enigmas, como la metáfora y la antítesis. ${ }^{15}$ También es llamativo que los enigmas sean incluidos en el mismo libro que los problemas matemáticos. Esto se podría explicar por la semejanza que existe entre unos y otros. Como indica Clearco en su definición, un enigma no es otra cosa que un tipo de problema.

El libro decimocuarto de Antología griega contiene 150 epigramas. Este no está dividido en partes, como se esperaría, sino que presenta problemas matemáticos, enigmas y oráculos de forma entremezclada: los epigramas 1-4, 6-7, 11-13, 48-51, 116-147 son problemas matemáticos; los epigramas 5, 9, 14, 16-47, 52-64, 101, 103, 105-106, 108 111 son enigmas; y los epigramas $65-100,148-150$ son oráculos. Los epigramas 8, 10, $15,102,104,107$ son difíciles de clasificar y, a primera vista, no corresponden a ninguno de los tres grupos mencionados. ${ }^{16}$

Por ser epigramas, la mayoría de los enigmas están escritos en verso. Todos son anónimos, con excepción del 63, que se atribuye a Mesomedes de Creta, y el 101, que se adjudica a Cleobulo de Lindos.

\section{2. Principales recursos para la composición de enigmas}

Félix Buffière propone clasificar los enigmas de Antología griega en dos grupos: enigmas en sentido estricto y enigmas en sentido amplio. ${ }^{17} \mathrm{Al}$ primer grupo, pertenecen

\footnotetext{
${ }^{14}$ Beckby 1958, p. 172 defiende que $\sigma 0 ́ \mu \mu 1 \kappa \tau \alpha$ también podría corresponder al título del libro XV.

${ }^{15}$ Cf. Fontenrose, Joseph (1978). The Delphic Oracle. Its Responses and Operations. Berkeley: University of California Press, pp. 79-83; Johnston, Sarah I. (2008). Ancient Greek Divination. Malden, MA: Wiley-Blackwell, pp. 51-56; y Naerebout, Frederick y Beerden, Kim (2013). “'Gods Cannot Tell Lies': Riddling and Ancient Greek Divination”. En Jan Kwapisz, David Petrain, y Mikołaj Szymański (eds), The Muse at Play. Riddles and Wordplay in Greek and Latin Poetry. Berlin: De Gruyter, pp. 125-142.

${ }^{16}$ Cameron 1993, pp. 208-210.

${ }^{17}$ Buffière, Félix (1970). Anthologie Grecque. Tome XII: Livres XIII-XV. Paris: Les Belles Lettres, pp. 45-49. Siguiendo la tesis de Buffière, Konstantakos, Ioannis M. (2004). "Trial by Riddle: The Testing of the Counsellor and the Contest of Kings in the Legend of Amasis and Bias". Classica et Mediaevalia 55, p. 120, defiende que el concepto de aiv $\gamma \mu \alpha$ refiere a los enigmas en sentido estricto y el de $\gamma$ ĩ $\varphi$ os, a los juegos de palabras. Una opinión diferente sostiene Luz, Christine (2013). "What Has It Got in Its Pocketses? Or, What Makes a Riddle a Riddle?" En Jan Kwapisz, David Petrain, y Mikołaj Szymański (eds), The Muse at Play. Riddles and
} 
aquellos que se ajustan a la definición aristotélica. Así, los enigmas en sentido estricto refieren a cosas que son (objetos, personajes, fenómenos o experiencias de la vida cotidiana que resultan familiares y conocidos) a través de descripciones que apuntan a entidades, personajes o sucesos extraños, poco probables o imposibles. Este tipo de descripciones permiten ocultar la solución y generan la apariencia de que el enigma habla de algo que se desconoce, cuando en realidad refiere a algo bien conocido. ${ }^{18}$ A modo de ejemplo, se puede mencionar $A G$ XIV 5, que describe el humo como un pájaro negro sin alas que se disuelve en el aire, y $A G$ XIV 19, que presenta al piojo como una bestia que corre sin apoyar las patas en el suelo. Algunos enigmas refieren a elementos que se encontraban usualmente en los simposios, como la flauta ( $A G$ XIV 14), el pescado ( $A G$ XIV 23, 36) y el vino ( $A G$ XIV 52), ya que allí era usual que los comensales participaran de competencias de acertijos ( $c f . A G$ XIV 26, 47, 53, 57, 58, 103). ${ }^{19}$ A su vez, dentro de este grupo, se distingue un conjunto particular de enigmas que apuntan a personajes o episodios míticos, como Andrómaca ( $A G$ XIV 9), Aquiles ( $A G$ XIV 18), Níobe ( $A G$ XIV 25), Tetis ( $A G$ XIV 27) o la muerte de Heracles ( $A G$ XIV 32-33) ( $c f . A G$ XIV 38, 44, 59, 63, 109). Estos se consideraban personajes y hechos bien conocidos porque los mitos formaban parte de la educación tradicional.

Los enigmas en sentido amplio, en cambio, son aquellos que consisten en juegos con palabras. La característica principal de estos enigmas es que, para hallar la respuesta, es necesario manipular el lenguaje y combinar sílabas o letras que puedan formar la palabra que constituye la solución. Al igual que los enigmas en sentido estricto, estas palabras refieren a objetos, personajes míticos o experiencias bien conocidos, que forman parte de la vida cotidiana. Por ejemplo, la solución de $A G$ XIV 16 es la isla de Rodas

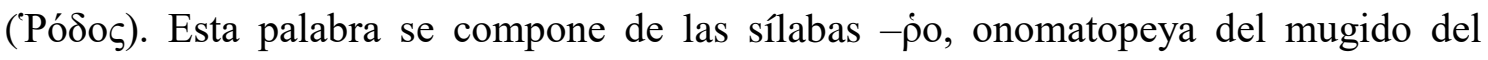

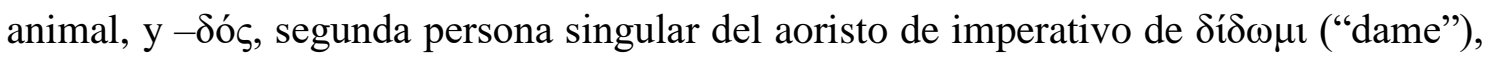
expresión utilizada frecuentemente por los acreedores. La solución de AG XIV 20 es

Wordplay in Greek and Latin Poetry. Berlin: De Gruyter, p. 98, quien señala que, en la mayoría

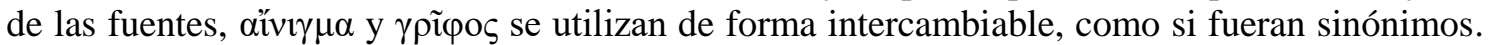
Sobre el sentido y uso de ambos términos, véase el extenso estudio lexicológico hecho por Berra 2008, pp. 75-269.

${ }^{18}$ Luz 2013, pp. 95-96.

${ }^{19}$ Sobre los enigmas en los simposios, $c f$. Della Bona, Maria Elena (2013). "Gare simposiali di enigmi e indovinelli”. Quaderni Urbinati di Cultura Classica 104 (2), pp. 169-182 y Potamiti,

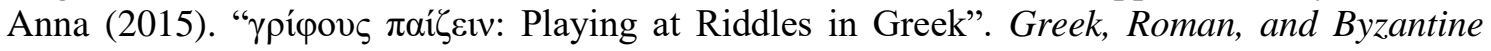
Studies 55, pp. 133-153. 
Pirro, también llamado Neoptólemo. En griego, el genitivo del sustantivo đũ $\rho$ ("fuego") es $\pi v \rho o ́ \varsigma$ y el número cien se representa con la letra $\rho$ '. Si en medio de la palabra $\pi v \rho o ́ \varsigma$

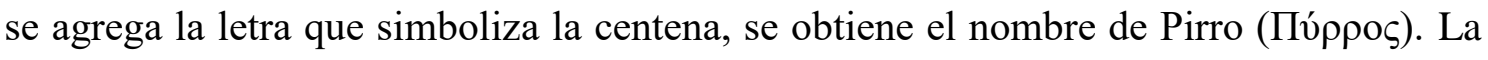

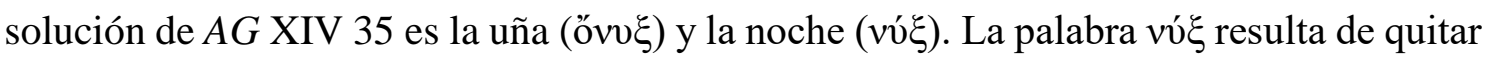
la letra inicial de la palabra ővv $\xi(c f . A G$ XIV 21, 31, 46, 105-106).

Para la composición de los enigmas de Antología griega, se utilizan con frecuencia algunos recursos retóricos como la metáfora, la metonimia, la ambigüedad, la antítesis y la personificación, cuyo conocimiento ayuda a comprender el sentido de los enunciados enigmáticos y hallar la respuesta. ${ }^{20}$ Según Aristóteles, la metáfora es el principal recurso para formular enigmas. Aristóteles define la metáfora como la transferencia del nombre propio ( $\kappa$ ṕpıv ővo $\mu \alpha$ ) de un ítem a otro ítem, al que este nombre se aplica de forma desplazada. ${ }^{21}$ Aristóteles distingue cuatro tipos de metáfora que tienen su base en cuatro tipos de transferencia nominal: la transferencia del nombre del género a una de las especies, del nombre de una de las especies al género, del nombre de una especie a otra especie, y la analogía. La metáfora por analogía se destaca entre las demás, ya que proporciona el caso más claro de la estructura fundamental que subyace a toda metáfora. ${ }^{22}$ La analogía establece que $b$ es a $a$ como $d$ es a $c$, de manera que es posible decir $b$ en lugar de $d$ y viceversa. Por ejemplo, dado que la copa de vino es a Dioniso lo que el escudo es a Ares, es posible llamar a la copa "escudo de Dioniso" y al escudo "copa de Ares" (Po. XXI 1457b16-19). Para proponer una analogía, es preciso percibir las semejanzas de los ítems entre los que se establece la analogía: "Pues formular buenas

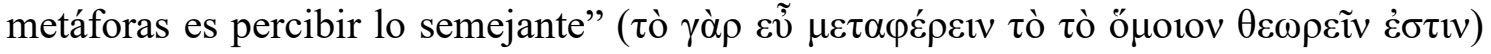
(Po. XXII 1459a7-8). El uso de metáforas basadas en analogías es útil en la composición

\footnotetext{
${ }^{20}$ Para ejemplificar el uso de estos recursos sólo tomo en consideración los enigmas que tienen solución y dejo de lado aquellos que no tienen respuesta. Sobre los recursos utilizados para la composición de los enigmas, $c f$. Luz 2013.

${ }^{21}$ Aristóteles, Po. XXI 1457b6-9: "La metáfora es la transferencia de un nombre ajeno, ya sea del género a una especie, de la especie al género, de la especie a otra especie, o por analogía"

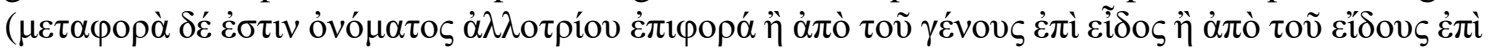

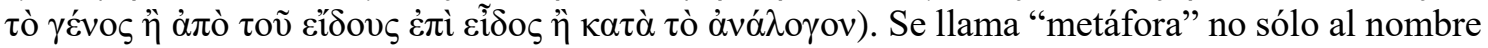
transferido, sino al proceso mismo de la transferencia que implica siempre una sustitución. $C f$. Laks, André (1994). "Substitution et connaissance: Une interprétation unitaire (ou presque) de la théorie aristotélicienne de la métaphore." En David J. Furley y Alexander Nehamas (eds), Aristotle's Rhetoric. Philosophical Essays. New Jersey: Princeton University Press, p. 284.

${ }^{22}$ Most, Glenn W. (1987). "Seeming and Being: Sign and Metaphor in Aristotle". En Mark Amsler (ed), Creativity and the Imagination. Case Studies from the Classical Age to the Twentieth Century. Newark: University of Delaware Press, pp. 19-20.
} 
de enigmas, ya que permite, por medio de la descripción de un objeto, referir a otro semejante. Por ejemplo, en $A G$ XIV 14, se establece una analogía entre la flauta doble y dos barcos; en $A G$ XIV 41, se habla metafóricamente de la salida del sol como un alumbramiento; en $A G$ XIV 59, se compara la nave de Argo con el vientre de una mujer; y en $A G$ XIV 101, se establece una analogía entre el año, los meses y los días, y un padre, sus hijos y sus nietos.

Para la composición de enigmas, también es frecuente el uso de la metonimia. Al igual que la metáfora, la metonimia consiste en una transferencia nominal que permite llamar a una cosa con el nombre de otra. Sin embargo, a diferencia de la metáfora, la sustitución propia de la metonimia no se funda en una analogía, sino en las relaciones de causalidad, procedencia, sucesión o contigüidad que existen entre las entidades envueltas en la metonimia. En lo que respecta a los enigmas, es usual el empleo de los nombres de las divinidades para referir metonímicamente a los elementos que son sus emblemas. Por ejemplo, al fuego se lo llama Hefesto ( $A G$ XIV 21, 53, 54, 109); al aceite, Palas ( $A G$ XIV 53); a la luz, Faetón ( $A G$ XIV 53); y al vino, Bromio ( $A G$ XIV 109). En sentido inverso, hay divinidades que son nombradas a través de los elementos que las representan. Por ejemplo, Apolo y Ártemis son llamados sol y luna ( $A G$ XIV 25), y Dioniso, vino ( $A G$ XIV 31) ( $c f . A G$ XIV 23, 37, 43, 45, 52, 54, 60).

Las descripciones enigmáticas son muchas veces ambiguas. La ambigüedad puede ser de dos tipos: sintáctica o semántica. Aristóteles llama a la ambigüedad sintáctica

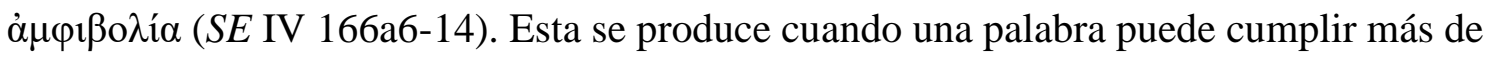
una función sintáctica en la oración. El ejemplo más claro se encuentra en $A G$ XIV 18:

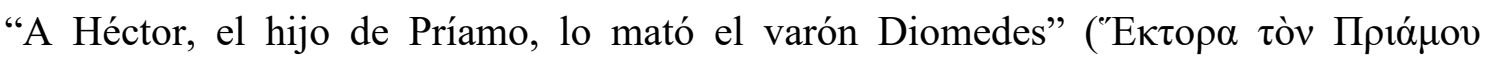

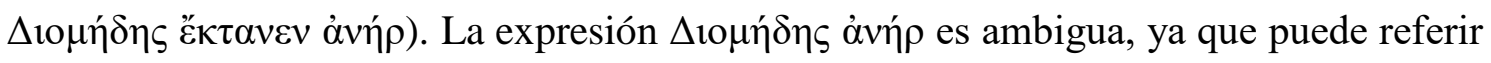
tanto al "varón Diomedes", i.e. el héroe aqueo que no mató a Héctor, como al "varón de Diomeda", i.e. Aquiles, el asesino del hijo de Príamo. Esto es posible porque el término $\Delta$ เo $\mu \eta ́ \delta \eta \varsigma$ puede ser, o bien la forma en nominativo del nombre masculino Diomedes $(\Delta 10 \mu \eta ́ \delta \eta \varsigma)$, o bien el genitivo del nombre femenino Diomeda ( $\Delta$ เo $\mu \eta ́ \delta \eta)$, la muchacha que Aquiles tomó luego de Briseida. La ambigüedad semántica se origina cuando se emplean palabras que poseen varios sentidos. Por ejemplo, en algunos enigmas se emplea el sustantivo кó $\eta$ que puede significar tanto "muchacha" como "pupila" (AG XIV 5, 109). En el enigma que describe los genitales masculinos, se explota el doble sentido de

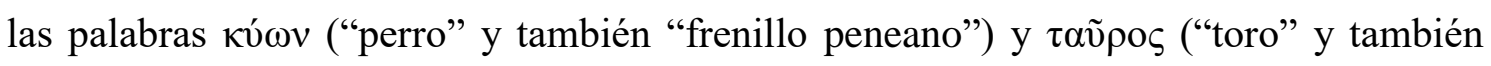
“ano") (AG XIV 43). Asimismo, a raíz de la semejanza morfológica entre el nombre 


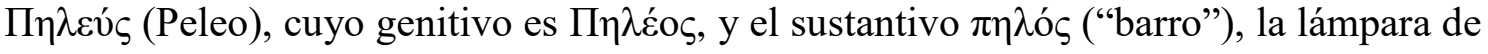
terracota es llamada "Peleo" y "recámara de Peleo" (AG XIV 37, 53).

Algunos enigmas presentan afirmaciones antitéticas que les dan el aspecto de verdaderas paradojas. Por ejemplo, "no hables y dirás mi nombre” ( $A G$ XIV 22); "una vez muerto, maté a quien me mató" ( $A G$ XIV 32); "digo cosas sin hablar" ( $A G$ XIV 45); "siendo inmortales, todos se consumen" ( $A G$ XIV 101); "cuando alguien mira, no me mira; pero si no mira, me ve" ( $A G$ XIV 110) ( $c f . A G$ XIV 9, 38, 41-42, 56).

La personificación, por medio de la cual se adjudica una cualidad propia de los animales humanos a objetos inanimados, también es un recurso frecuente en la formulación de enigmas. La personificación se enfatiza cuando el enigma se expresa en primera persona. Por ejemplo, la toalla de lino dice que disfruta de un baño agradable ( $A G$ XIV 26), la cera se muestra capaz de decir cosas sin hablar $(A G$ XIV 45, 60) y el vino confiesa haber llorado la muerte de Polifemo ( $A G$ XIV 52) ( $c f . A G$ XIV 29, 54, 56, $59,62,103,110)$.

\section{Traducción}

\section{1. Traducción de los enigmas de Antología griega}

\section{$A G$ XIV 5}

Soy hijo negro de padre blanco, pájaro sin alas que vuela hasta las nubes del cielo.

En las pupilas que se me acercan, engendro lágrimas libres de dolor. Apenas nazco, me disuelvo en el aire.

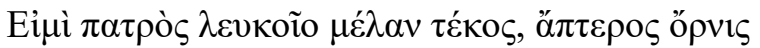

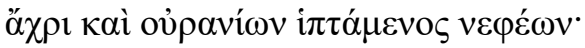

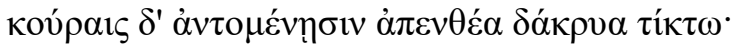

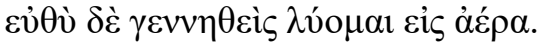

$A G$ XIV 9

A mi esposo lo mató mi suegro; a mi suegro lo mató mi esposo; a mi suegro, mi cuñado; y a mi padre, mi suegro.

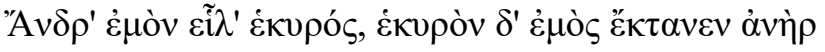

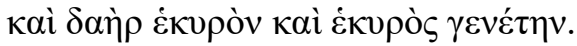

$A G$ XIV 14

Un viento, dos barcos, diez marineros reman y un capitán conduce a ambos.

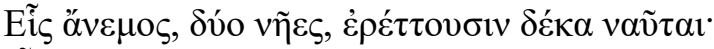

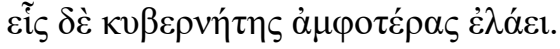


$A G$ XIV 16

Mugido de buey más palabra de prestamista, en total una isla.

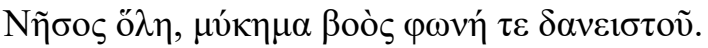

$A G$ XIV 18

A Héctor, el hijo de Príamo, lo mató el varón Diomedes, mientras peleaba con su espada por la tierra de los troyanos.

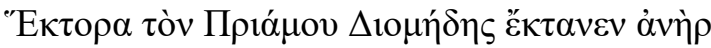

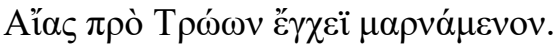

$A G$ XIV 19

Vi una vez a una bestia, a través de un bosque cortado con acero, correr de espaldas en línea recta, sin tocar con las patas el suelo.

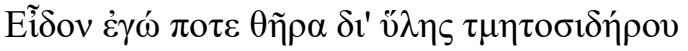

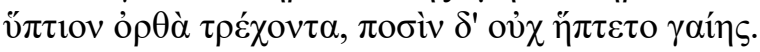

$A G$ XIV 20

$\mathrm{Si}$ en medio del fuego ardiente colocas cien, encontrarás al hijo y asesino de una virgen.

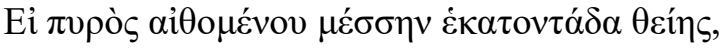

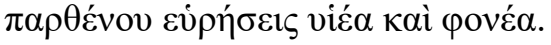

\section{$A G$ XIV 21}

Si en medio de Hefesto sólo arrojas cien, encontrarás al hijo y asesino de una virgen.

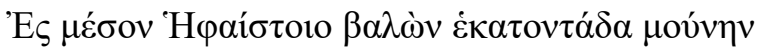

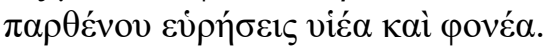

$A G$ XIV 22

No hables y dirás mi nombre. ¿Pero es necesario que hables?

Entonces, una vez más, gran sorpresa: hablando dirás mi nombre.

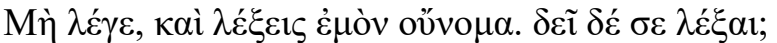

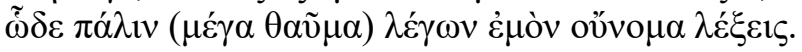

$A G$ XIV 23

Por ser hijo de Nereo, me lleva un hijo de la tierra, sumergido en las agradables aguas del Estigia.

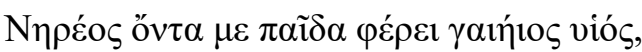

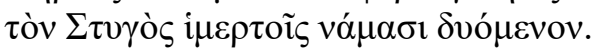

\section{$A G$ XIV 24}

Me miras a mí, un Dioniso humano.

Un vientre doble me dio a luz y mi padre gobierna la memoria.

Este me engendró primero a mí, como una criatura despiadada que transporta una bestia. Tras matar al amado hijo de mi propia hermana, que es una sierva, ya no llevo una bestia, sino el cielo, el mar, la tierra y el sagrado coro de felices dioses, siempre inmortal.

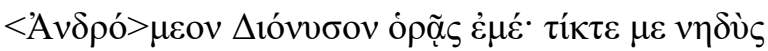

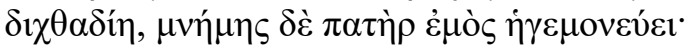

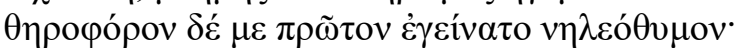




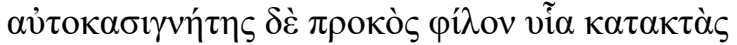

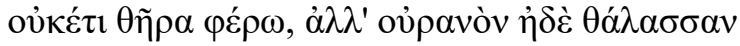

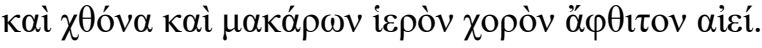

$A G$ XIV 25

Echo de menos los ojos de Escila, los que el mismo sol y la luna hicieron desaparecer. Cuando era niña, mi padre me temía.

Muerta, me baño en dos ríos inmortales que mi cabeza deja caer por la elevada colina.

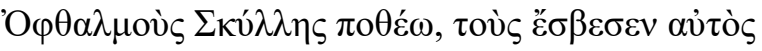

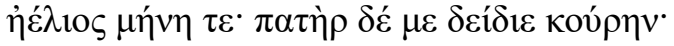

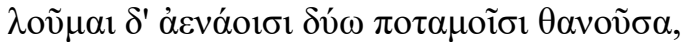

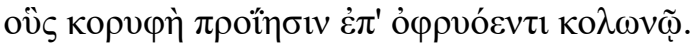

$A G$ XIV 26

Yo era antes algo amarilla, pero al ser cortada, me he vuelto más blanca que la nieve blanca.

Disfruto de un baño agradable y lleno de peces si voy primero al encuentro de los invitados.

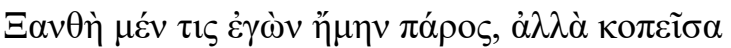

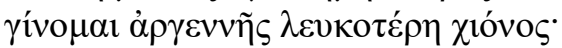

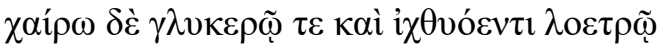

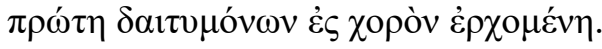

\section{$A G$ XIV 27}

Buscando en el mar a la joven que antes era una leona, encontrarás a la suegra de Hécuba, la asesina de niños.

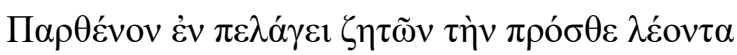

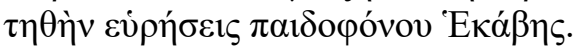

\section{$A G$ XIV 28}

Por el mar, me tocó en suerte un linaje ictícola.

Una hazaña supo cómo llevarme a las competencias dionisíacas.

Tras untarme el cuerpo con aceite en el estadio, al hijo de Deméter mato con mis manos.

Luego, expulso a una multitud de Gigantes que vienen de todas partes, arrastrados por muchas manos.

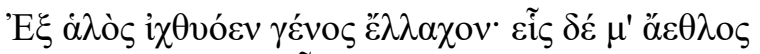

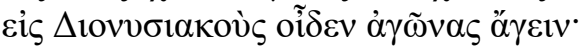

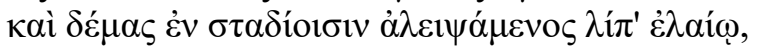

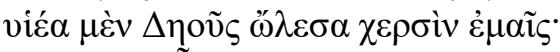

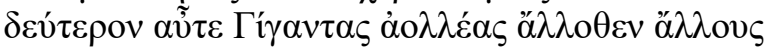

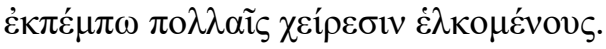

\section{$A G$ XIV 29}

Sólo a mí me gusta tener sexo con las mujeres cuando sus maridos lo piden.

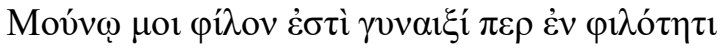

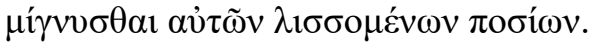

$A G$ XIV 30

Tengo como padre a un carnero y por él una tortuga me dio a luz. 
$\mathrm{Al}$ nacer, maté a mis dos padres.

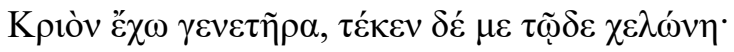

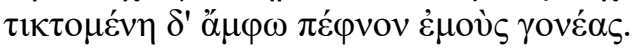

$A G$ XIV 31

Escribe a la otra madre del vino, agrega un artículo al artículo y verás que su patria es la esposa del padre.

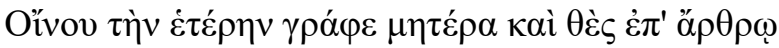

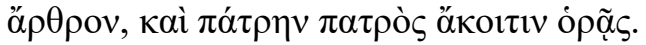

$A G$ XIV 32

Una vez muerto, maté a quien me mató, pero este no fue al Hades. En verdad, morí yo.

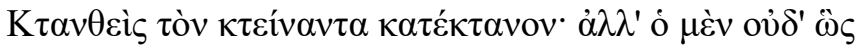

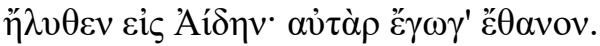

$A G$ XIV 33

Maté al que me mató, pero no me resultó placentero, pues al asesino inmortal lo hizo la muerte.

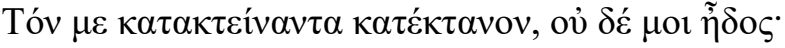

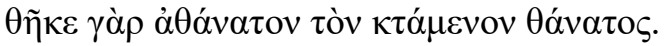

$A G$ XIV 35

Del hombre soy una parte, la que con hierro me corta. Si me quitan una letra, el sol se oculta.

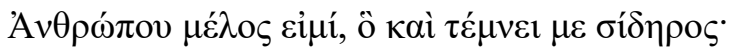

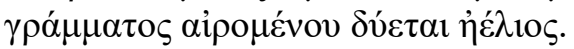

$A G$ XIV 36

Para mí, la vida es amarga; la muerte, dulce; pero ambas, agua. Sin dejar rastros de sangre, muero atravesado por arpones.

Si alguien me enterrara, como a un cadáver, en una tumba viviente, me humedecería con la sangre de mis parientes.

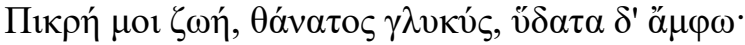

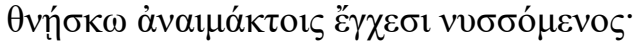

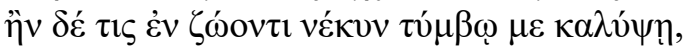

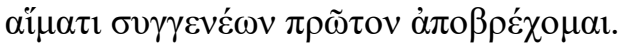

$A G$ XIV 37

Soy querido por Palas y doy a luz innumerables hijos que los hombres lanzan desde las rocas.

Una vez muertos, son luz de Peleo, remedio para los mortales, defensa en las batallas.

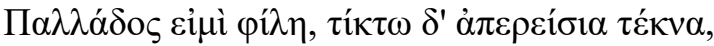

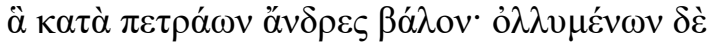

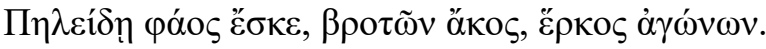

$A G$ XIV 38

Maté a mi hermano, mi hermano me mató y fuimos asesinados por nuestro padre. Una vez muertos, ambos matamos a nuestra madre.

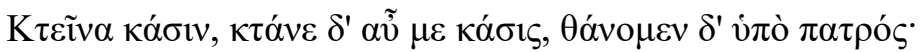

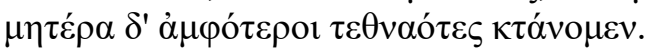


$A G$ XIV 39

Si alguien me llama "isla" no mentirá, pues le pone mi nombre, y con verdad, a muchas aguas bravas.

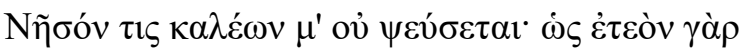

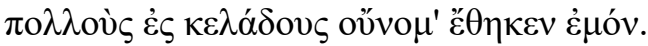

$A G$ XIV 40

Existen dos hermanas gemelas.

Una da a luz a la otra y esta, luego de parir, nace de ella, de modo que, siendo hermanas y de la misma sangre, son a la vez hermanas y madres.

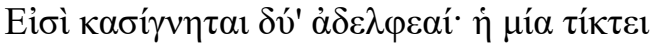

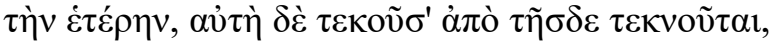

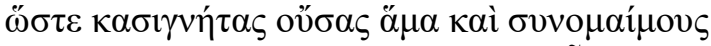

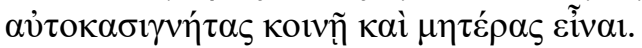

$A G$ XIV 41

A mi madre doy a luz y soy dado a luz por ella.

Algunas veces soy más grande que ella; otras, más pequeña.

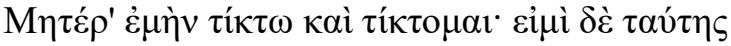

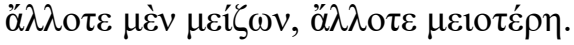

\section{$A G$ XIV 42}

Soy una mujer virgen, hija de una mujer virgen $\mathrm{y}$, a pesar de ser una mujer virgen, doy a luz cada año.

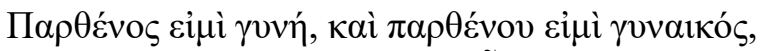

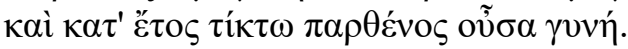

\section{$A G$ XIV 43}

Del eje de la tierra soy imitación.

Dos bestias me transportan: al frente, la de Erígone; por detrás, la de Pasífae. La esposa de Heracles me cuida, pero la querida mujer de Febo, quemándome, muchas veces me lastima.

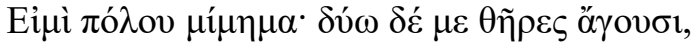

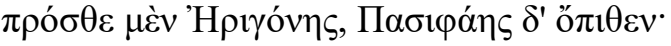

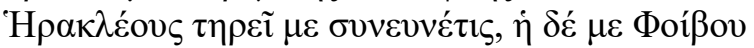

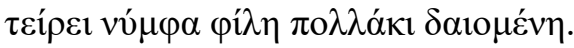

\section{$A G$ XIV 44}

En una sola noche, ataqué a los troyanos $\mathrm{y}$, al dividirlos, derroté sin la lanza a la tribu de los pelasgos.

$\mathrm{Ni}$ el Tidida ni Odiseo, el saqueador de ciudades, pudieron empujarme a mí, el valiente, fuera de la nave. Mientras aumentaba en mi pecho la fuerza y el coraje, destruí al ejército de los argivos y los frigios.

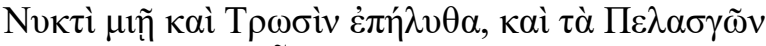

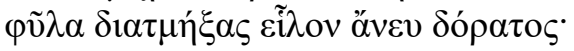

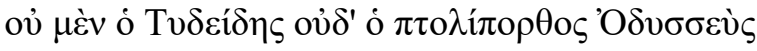

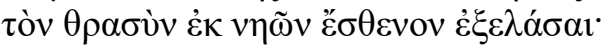

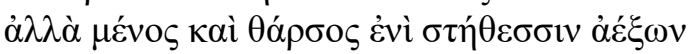

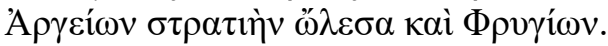


$A G$ XIV 45

Soy negra, blanca, amarilla, seca y también húmeda. Cuando me extiendes sobre una llanura de madera, gracias a Ares y a la mano, digo cosas sin hablar.

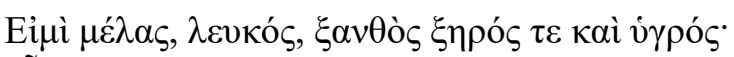

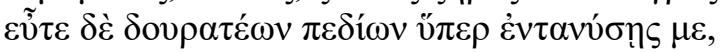

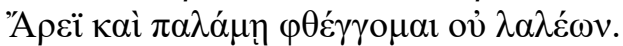

$A G$ XIV 46

Si se agrega una letra, mi nombre produce un golpe en el pie.

Si no, mi nombre jamás permitirá que los pies de los hombres se tropiecen.

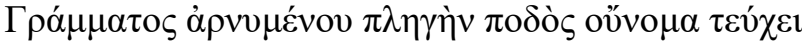

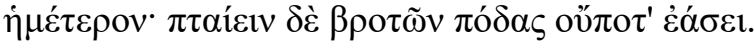

$A G$ XIV 47

Por la luz, yo perdí la luz, pero alguien que estaba cerca de la luz la querida luz me entregó, haciéndole a sus pies un favor.

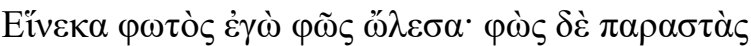

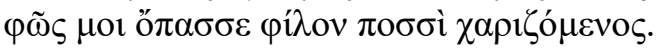

$A G$ XIV 52

Hubo un tiempo en que, luchando con los lapitas y el vigoroso Heracles, destruí a los centauros de naturaleza doble.

Hubo un tiempo en que, de tres de mis flechazos, murió la pupila solitaria y me lamenté por el hijo de Cronos que habita en el mar.

Ahora, la tercera Musa me ve mezclado con las ardientes ninfas y recostado en suelo de cristal.

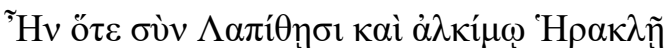

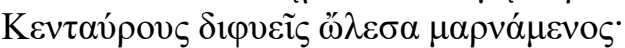

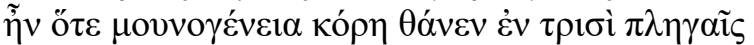

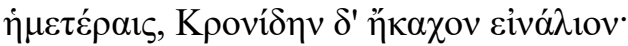

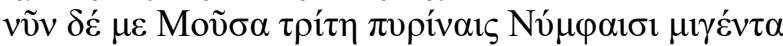

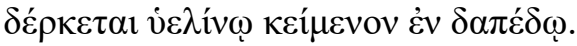

$A G$ XIV 53

Dominada por sus brazos, se mezcla Palas con Hefesto

en la cama de la recámara de Peleo.

Cuando se tapan con brillantes telas,

nace inmediatamente Faetón, que se agita por la noche.

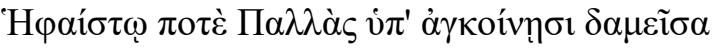

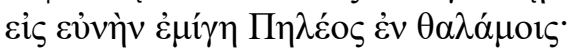

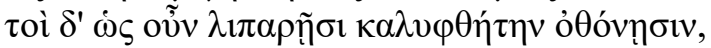

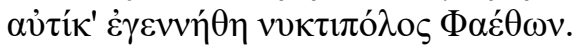

\section{$A G$ XIV 54}

El ingenioso arte de Peán me hizo encerrar el fuego

que aún respira detrás de mis labios de bronce.

Mientras extraigo la oscura sangre de los miserables hombres, mato a Hefesto encerrándolo en mi vientre.

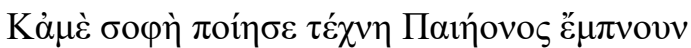

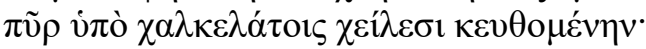




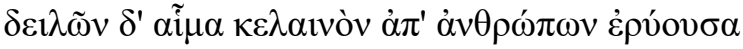

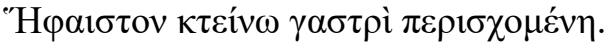

\section{$A G$ XIV 55}

Sólo a mí me está permitido tener sexo con las mujeres

cuando sus maridos lo piden.

Yo solo me monto a jovencitos, varones adultos, ancianos y vírgenes

mientras sus padres se lamentan.

La lujuria... la detesto. Me ama la mano sanadora

cuando realizo el trabajo del hijo de Anfitrión.

A favor de los casados, podría pelear incluso contra Plutón

para defender las almas de aquellos con quienes tengo sexo.

Gracias al conocimiento de los mortales, un elefante mezclado con una cabra

me produce a mí, un niño con buena nariz y blanca sonrisa.

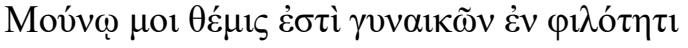

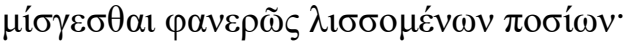

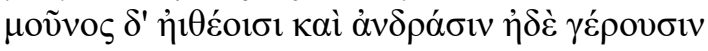

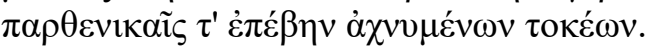

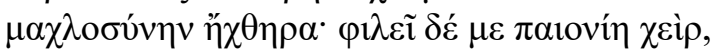

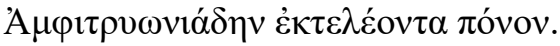

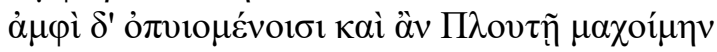

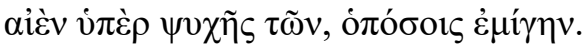

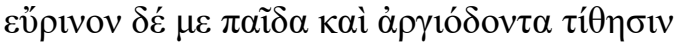

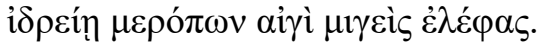

$A G$ XIV 56

Cada vez que me miras, yo también te miro.

Tú me miras con los ojos, pero yo, sin los ojos porque no tengo ojos.

Cada vez que tienes ganas, puedo pronunciar palabras sin voz

porque tú tienes voz, pero yo, labios que se abren en vano.

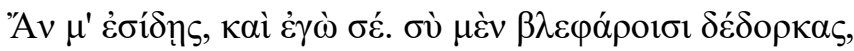

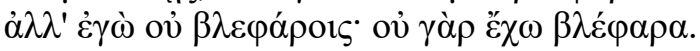

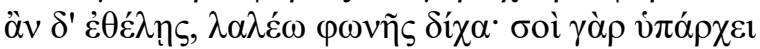

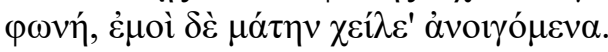

\section{$A G$ XIV 57}

El nombre de mi madre tengo, más dulce que mi madre soy.

Ella es alta, yo soy pequeño.

Ella es incomible (salvo por la cabeza),

pero yo soy todo comestible (sólo tengo intestinos incomibles).

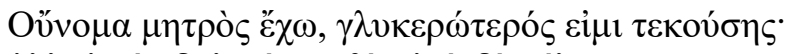

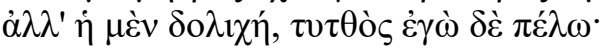

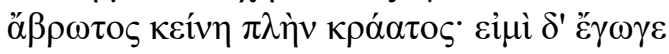

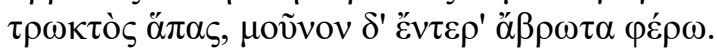

$A G$ XIV 58

Cerebro tengo sin cabeza.

Soy verde y me levanto desde la tierra gracias a mi largo cuello.

Como una pelota sobre una flauta me veo.

Si buscas en mi vientre, allí tengo al padre de mi madre.

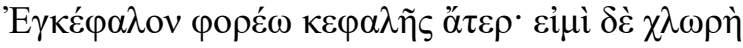

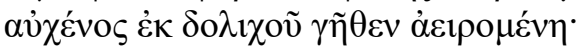

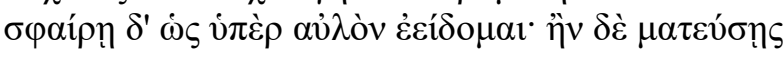

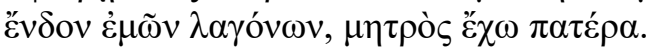


$A G$ XIV 59

Tras concebir en mi único vientre a cincuenta hijos, de todos los ladrones al líder maté.

Este ha muerto dos veces, dado que dos vientres lo parieron, uno de bronce y antes uno humano.

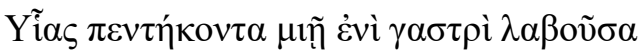

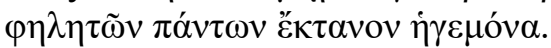

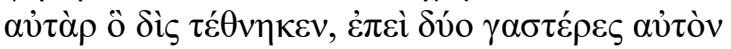

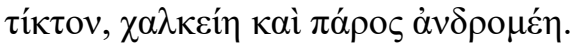

\section{$A G$ XIV 60}

El bosque me parió, el hierro me hizo.

Soy misterioso reservorio de las Musas.

Encerrada, guardo silencio, pero cuando me descubren,

hablo con Ares, a quien tengo como único confidente de mis palabras.

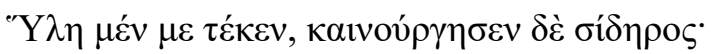

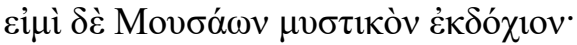

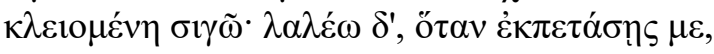

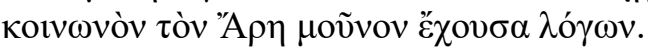

\section{$A G$ XIV 61}

Nací en las montañas, a un árbol tuve como madre,

al fuego como padre y soy suelo ennegrecido.

Si dentro de una vasija de barro mi padre me disolviera,

protegería de las heridas al fuerte carro del mar.

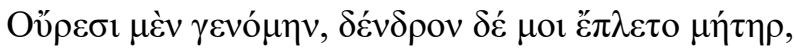

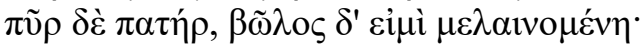

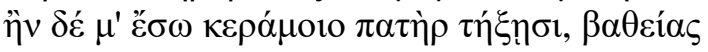

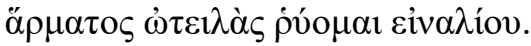

\section{$A G$ XIV 62}

Soy muy peluda.

Las hojas cubren mis cabellos para que no se me vea ningún agujero.

Con muchos niños pequeños juego.

Si alguno no es bueno para lanzar, se quedará parado como un tonto.

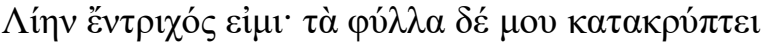

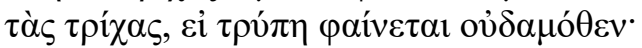

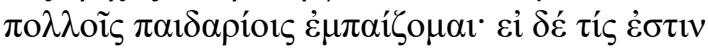

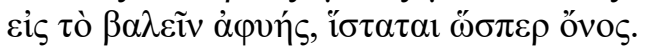

\section{$A G$ XIV 63}

Camina lentamente, se detiene, vuela,

levanta un pie bastardo en la carrera.

De frente, es una mujer alada,

tiene el cuerpo de una leona que ruge

y en la espalda, una cola de serpiente enroscada.

No corría como un reptil, ni como una mujer,

ni como un pájaro de cuerpo entero, ni como una bestia.

Parecía una muchacha sin pies,

la bestia que ruge no tenía cabeza.

Su naturaleza era de composición irregular,

una mezcla de partes imperfectas y perfectas. 


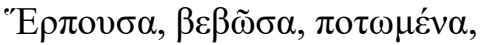

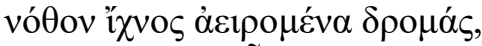

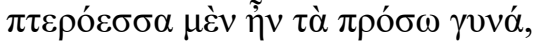

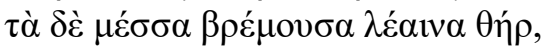

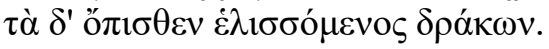

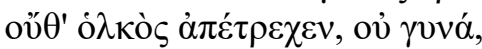

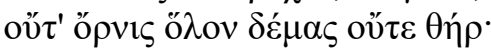

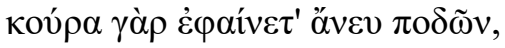

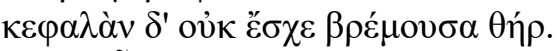

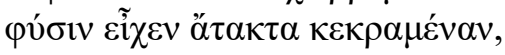
$\dot{\alpha} \tau \dot{\varepsilon} \lambda \varepsilon \sigma \tau \alpha \tau \dot{\varepsilon} \lambda \varepsilon 1 \alpha \mu \varepsilon \mu 1 \gamma \mu \varepsilon \dot{v} \alpha$.

\section{$A G$ XIV 64}

Existe sobre la tierra una criatura con dos pies, cuatro pies y tres pies, cuya voz es una sola. Simplemente, cambia su naturaleza como las bestias que se mueven en la tierra, a través del cielo y debajo del mar. Cuando camina apoyada en la mayor cantidad de pies, en ese momento, la velocidad de sus extremidades se debilita.

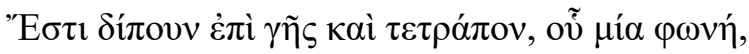

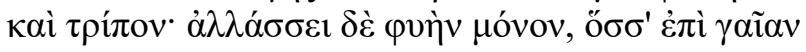

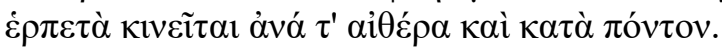

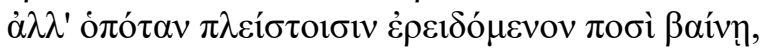

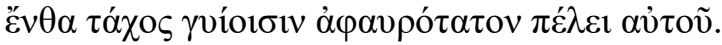

\section{$A G$ XIV 101}

Uno el padre, doce los hijos. Para cada uno de ellos, dos veces treinta hijos de apariencia doble.

Unos se ven claros; otros, por el contrario, oscuros.

Siendo inmortales, todos se consumen.

Eĩ

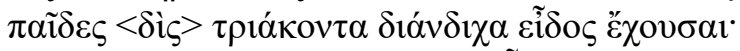

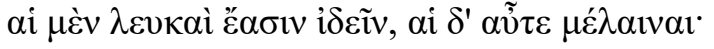

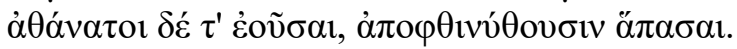

\section{AG XIV 103}

Si me hubieras agarrado joven, rápidamente habrías bebido mi sangre, pero ahora que el tiempo me ha hecho vieja, cómeme arrugada, sin nada de humedad, rompiendo mis huesos con mi carne.

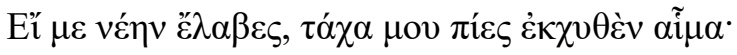

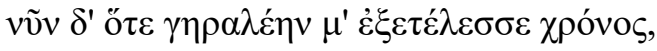

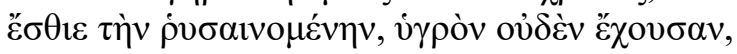

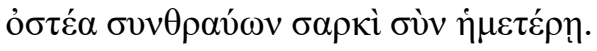

$A G$ XIV 105

De los animales soy una parte que busca el suelo.

Si me quitas sólo una letra, de la cabeza una parte me vuelvo.

Si me quitas otra, animal otra vez seré.

Si también otra, no me descubrirás como uno solo, sino como doscientos.

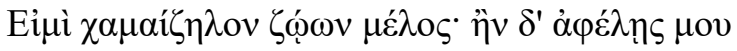

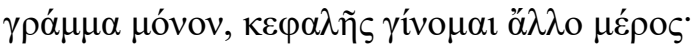

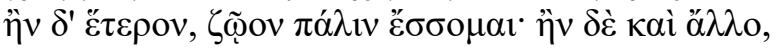

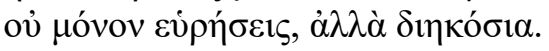


AG XIV 106

Con cuatro letras, recorro un camino.

Si quitas la primera letra, escucho.

Si quitas la que sigue, me descubrirás como un amante del lodo.

Si quitas la última, descubrirás a continuación un adverbio de lugar.

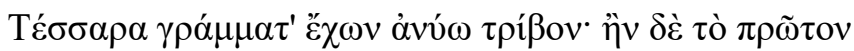

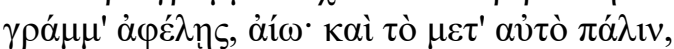

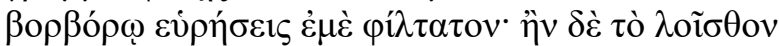

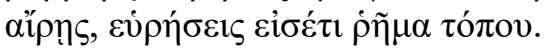

$A G$ XIV 108

No tengo nada dentro y todo está dentro de mí.

Como un regalo, concedo a todos la gracia de mi virtud.

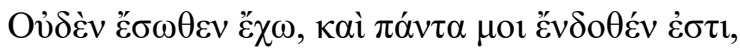

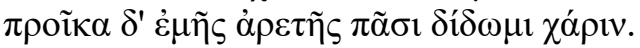

$A G$ XIV 109

Consumida por el fuego, murió una muchacha dormida.

El traidor, el vino. Aquello que causó su muerte, un tronco de Palas.

El asesino, el responsable del naufragio.

Yace en una tumba viviente por culpa de los favores de Bromio.

A la muchacha solitaria destruyeron Palas, Bromio y el glorioso dios de las piernas cojas.

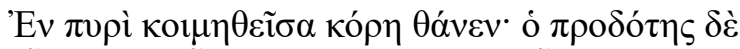

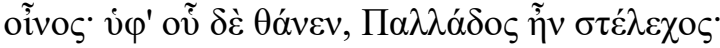

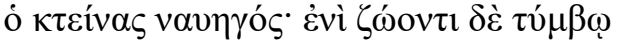

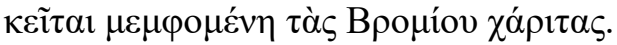

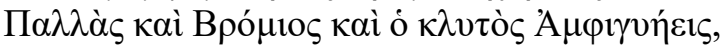

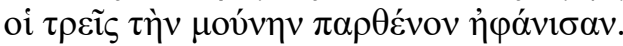

$A G$ XIV 110

Cuando alguien mira, no me mira; pero si no mira, me ve.

El que no habla habla, el que no corre corre.

Hago trampa, pero todo lo que digo es verdad.

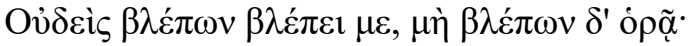

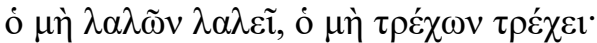

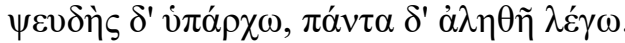

$A G$ XIV 111

Un hijo sin hijos, hijo de padres sin hijos, portador de dardos, niño, fuerte.

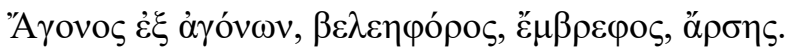

\section{2. Solución de los enigmas de Antología griega}

Los manuscritos del libro decimocuarto de Antología griega no transmiten la solución de todos los enigmas, sino sólo de $A G$ XIV 5, 22, 26, 35, 41, 52-60, 62, 64, 103. Para el resto, los editores y traductores del texto han sugerido diversas soluciones. Algunos enigmas son difíciles de descifrar y, aún hoy, se encuentran sin solución. 
$A G$ XIV 5: El humo.

$A G$ XIV 9: Andrómaca. Héctor, el primer esposo de Andrómaca, fue asesinado por Aquiles, el padre de Neoptólemo, que fue el segundo esposo de Andrómaca. Neoptólemo mató a Príamo, el padre de Héctor. Paris, el hermano de Héctor, mató a Aquiles. Aquiles mató a Eetión, el padre de Andrómaca.

$A G$ XIV 14: La flauta doble.

$A G$ XIV 16: La isla de Rodas.

$A G$ XIV 18: Aquiles.

$A G$ XIV 19: El piojo.

AG XIV 20-21: Pirro, también llamado Neoptólemo. Este era hijo de Deidamía y Aquiles. Asesinó a Políxena, la hija de Hécuba y Príamo.

$A G$ XIV 22: El silencio.

$A G$ XIV 23: Un pez muerto en una vasija de barro llena de agua ( $c f . A G$ XIV 36).

$A G$ XIV 24: Solución desconocida.

$A G$ XIV 25: Níobe. Esta había tenido catorce hijos y se burlaba de Leto, quien sólo había dado a luz a Apolo y Artemisa. Enojada, Leto pidió a sus hijos que la vengaran. Estos asesinaron a doce de los hijos de Níobe, que en el enigma son comparados con los doce ojos de Escila. Luego de esta desgracia, Níobe huyó al monte Sípilo donde los dioses la transformaron en una roca que nunca dejaba de llorar.

$A G$ XIV 26: La toalla de lino.

$A G$ XIV 27: Tetis. Intentando huir de Peleo, quien terminó casándose con ella, Tetis se transformó en un león. Hécuba es uno de los nombres de Medea, quien, según algunas versiones del mito, se casó con Aquiles, el hijo de Tetis, en la Isla de los Bienaventurados.

$A G$ XIV 28: Solución desconocida.

$A G$ XIV 29: El enema ( $c f . A G$ XIV 55).

$A G$ XIV 30: Solución desconocida.

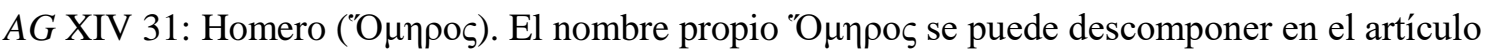
masculino singular ó y el sustantivo $\mu \eta \rho$ ó ("muslo"). Dioniso es hijo de Zeus y Sémele. Cuando esta estaba embarazada, murió porque no pudo resistir la visión de los rayos de Zeus. Zeus tomó al hijo que estaba en su vientre y lo cosió en su muslo, donde lo terminó de gestar y lo alumbró. Una de las ciudades que se señala como lugar de nacimiento de Homero es Esmirna $(\Sigma \mu v ́ \rho v \alpha)$. Este nombre coincide con el de la mirra $(\sigma \mu v ́ \rho v \alpha)$, el principal producto de exportación de la ciudad, y con el de la madre de Adonis, quien tuvo una relación incestuosa con su padre.

$A G$ XIV 32-33: Neso, el centauro que recibió un flechazo de parte de Heracles cuando intentaba violar a su esposa Deyanira. Antes de morir, Neso engañó a la mujer diciéndole que su sangre le aseguraría el amor del héroe, cuando en realidad se trataba de un veneno que provocaría su muerte. Heracles trasciende su muerte porque, gracias a sus hazañas, alcanza una fama inmortal ( $c f$. $A G$ XIV 52).

$A G$ XIV 35: La uña (ővv $\xi$ ) y la noche (vớ).

$A G$ XIV 36: El pez. Las últimas líneas podrían referir a los alimentos con los que el pescado se mezcla ( $c f . A G$ XIV 23).

$A G$ XIV 37: El olivo.

$A G$ XIV 38: Eteocles y Polinices, hijos de Edipo y Yocasta.

$A G$ XIV 39: Solución desconocida. 
$A G$ XIV 40-41: El día $(\dot{\eta} \mu \varepsilon ́ \rho \alpha)$ y la noche (vóg). En griego, ambas palabras son de género femenino.

$A G$ XIV 42: Solución desconocida.

$A G$ XIV 43: Este enigma presentaría una descripción de los genitales masculinos. La bestia de

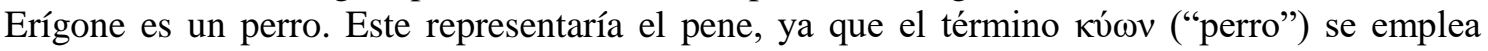
también para nombrar el frenillo peneano. Pasífae es la madre del minotauro. Este representaría el ano, ya que el sustantivo $\tau \alpha \tilde{v} \rho o \varsigma$ ("toro") tiene también esta acepción. La esposa de Heracles es Hebe, la diosa de la juventud. Esta representaría el vello púbico ( $\left.\eta_{\beta \eta}\right)$ que aparece en esta etapa de la vida, cuyo nombre coincide con el de la diosa. La esposa de Febo es Dafne, cuyo nombre es

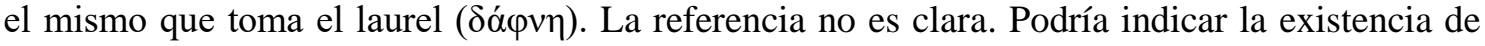
algún ungüento hecho a base de laurel que se aplicaba en la zona genital.

$A G$ XIV 44: El sueño de Agamenón ( $c f$. Homero, Il. II 1-71).

$A G$ XIV 45: La cera con que se cubren las tablillas utilizadas para escribir ( $c f$. $A G$ XIV 60).

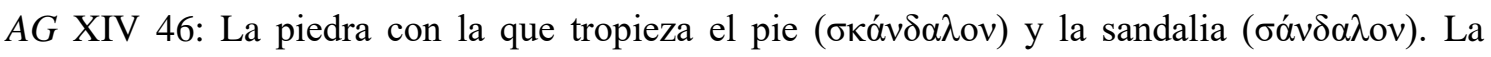
diferencia entre ambas palabras es la presencia de la letra $\kappa$.

$A G$ 14. 47: La lámpara ( $c f . A G$ XIV 53).

$A G$ 14. 52: El vino. El enigma hace referencia a episodios míticos en los que el vino jugó un importante papel. Por una parte, se alude a la muerte de Heracles ( $c f . A G$ XIV 32-33) y a la batalla entre centauros y lapitas. Esta se desató cuando los centauros, invitados a la boda de Pirítoo, rey de los lapitas, bebieron en exceso y quisieron violar a las mujeres de la fiesta. Por otra parte, la pupila solitaria hace referencia al único ojo de Polifemo. Este había tomado como prisioneros a Odiseo y su tripulación. Para escapar, Odiseo le dio una gran cantidad de delicioso vino. Cuando Polifemo se quedó dormido a causa de la borrachera, Odiseo le clavó una estaca en su único ojo, dejándolo ciego ( $c f$. Homero, Od. IX 105-542; AG XIV 109). Las ardientes ninfas representan el agua caliente y el suelo de cristal, la copa donde se sirve el vino. La tercera musa es Erató, que está asociada con la poesía amorosa.

$A G$ XIV 53: La lámpara ( $c f . A G$ XIV 47).

$A G$ XIV 54: La ventosa (cf. supra n. 7).

$A G$ XIV 55: El enema ( $c f . A G$ XIV 29).

$A G$ XIV 56: El espejo ( $c f . A G$ XIV 108).

$A G$ XIV 57: El dátil de la palmera. Este recibe en griego los nombres de $\beta \alpha ́ \lambda \alpha v o \varsigma$ y $\varphi$ oĩvı $\xi$. Este último término también se utiliza para nombrar la palmera.

$A G$ XIV 58: La alcachofa.

$A G$ XIV 59: Argo, la nave en que navegaron Jasón y sus compañeros, los argonautas, en busca del vellocino de oro.

$A G$ XIV 60: La tablilla de escribir ( $c f . A G$ XIV 45).

$A G$ XIV 61: Solución desconocida.

$A G$ XIV 62: La pelota.

$A G$ XIV 63: La Esfinge ( $c f . A G$ XIV 64).

$A G$ XIV 64: Una persona que atraviesa las distintas etapas de la vida: gatea cuando es bebé; a medida que crece, camina con sus dos piernas; y al llegar a la vez, usa un bastón ( $c f$. Apolodoro, Bibl. III 5.8; Ateneo X 456b). Este es el enigma de la Esfinge ( $c f . A G$ XIV 63).

$A G$ XIV 101: El año, los meses y los días. Este enigma también se atribuye a Cleobulina ( $c f$. Suda, s. v. Cleobulina).

$A G$ XIV 103: La pasa de uva. 
$A G$ XIV 105: A través de la supresión de la letra inicial de la palabra, el acertijo refiere al pie

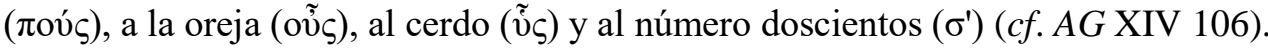

$A G$ XIV 106: A través de la supresión de la letra inicial de la palabra, el acertijo refiere al pie ( $\pi \circ v_{\varsigma}$ ), a la oreja (oṽ $\varsigma$ ) y al cerdo (ṽ்). Luego, manteniendo todas las letras y suprimiendo sólo la final, la respuesta es el adverbio de lugar $\pi$ oṽ (“¿dónde?”) ( $c f . A G$ XIV 105).

$A G$ XIV 108: Solución desconocida. Podría tratarse del espejo ( $c f . A G$ XIV 56).

$A G$ XIV 109: El ojo de Polifemo ( $c f . A G$ XIV 52).

$A G$ XIV 110: El sueño.

$A G$ XIV 111: Solución desconocida.

Mariana Gardella

Instituto de Investigaciones Filosóficas - Universidad Nacional Autónoma de México

\section{Referencias bibliográficas}

Beckby, Hermann (1958). Anthologia Graeca. Bd. 4: Buch XII-XVI. München: Heimeran.

Berra, Aurélien (2008). Théorie et pratique de l'énigme en Grèce ancienne. Paris: École des Hautes Études en Sciences Sociales.

Beta, Simone (2016). Il labirinto della parola. Enigmi, oracoli e sogni nella cultura antica. Torino: Einaudi.

Bing, Peter y Bruss, Jon S. (2007). "Preface". En Peter Bing y Jon S. Bruss (eds), Brill's Companion to Hellenistic Epigram. Down to Philip. Leiden-Boston: Brill, pp. 1-26.

Buffière, Félix (1970). Anthologie Grecque. Tome XII: Livres XIII-XV. Paris: Les Belles Lettres. Cameron, Alan (1993). The Greek Anthology. From Meleager to Planudes. Oxford: Clarendon Press.

Colli, Giorgio (1977). La sapienza greca. Vol. I: Dioniso, Apollo, Eleusi, Orfeo, Museo, Iperborei, Enigma. Milano: Adelphi.

Della Bona, Maria Elena (2013). "Gare simposiali di enigmi e indovinelli". Quaderni Urbinati di Cultura Classica 104 (2), pp. 169-182. DOI: 10.1400/216327

Fontenrose, Joseph (1978). The Delphic Oracle. Its Responses and Operations. Berkeley: University of California Press.

Gardella, Mariana y Juliá, Victoria (2018). El enigma de Cleobulina. Buenos Aires: Teseo. URL: https://www.teseopress.com/elenigmadecleobulina

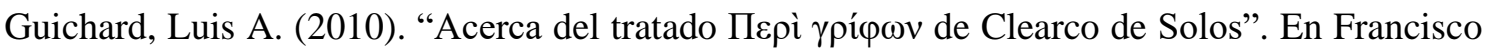
Cortés Gabaudán y Julián V. Méndez Dosuna (eds), Dic mihi, Musa, virum. Homenaje al Profesor 
Antonio López Eire. Salamanca: Ediciones Universidad de Salamanca, pp. 285-291.

Johnston, Sarah I. (2008). Ancient Greek Divination. Malden, MA: Wiley-Blackwell.

Kaivola-Bregenhøj, Annikki (2001). Riddles. Perspectives on the Use, Function and Change in a Folklore Genre. Helsinki: Studia Fennica Folkloristica. URL: http://library.oapen.org/ handle/20.500.12657/32109

Köngäs Maranda, Elli (1969). "Structure des énigmes”. L'Homme 9 (3), pp. 5-48.

Konstantakos, Ioannis M. (2004). "Trial by Riddle: The Testing of the Counsellor and the Contest of Kings in the Legend of Amasis and Bias". Classica et Mediaevalia 55, pp. 85-138.

Laks, André (1994). "Substitution et connaissance: Une interprétation unitaire (ou presque) de la théorie aristotélicienne de la métaphore". En David J. Furley y Alexander Nehamas (eds), Aristotle's Rhetoric. Philosophical Essays. New Jersey: Princeton University Press, pp. 283-305.

Luz, Christine (2010). Technopaignia. Formspiele in der griechischen Dichtung. Leiden-Boston: Brill.

Luz, Christine (2013). "What Has It Got in Its Pocketses? Or, What Makes a Riddle a Riddle?". En Jan Kwapisz, David Petrain, y Mikołaj Szymański (eds), The Muse at Play. Riddles and Wordplay in Greek and Latin Poetry. Berlin: De Gruyter, pp. 83-99.

Matelli, Elisabetta (1997). "Sulle tracce di Cleobulina”. Aevum 71 (1), pp. 11-61.

Most, Glenn W. (1987). "Seeming and Being: Sign and Metaphor in Aristotle". En Mark Amsler (ed), Creativity and the Imagination. Case Studies from the Classical Age to the Twentieth Century. Newark: University of Delaware Press, pp. 11-33.

Naerebout, Frederick y Beerden, Kim (2013). “'Gods Cannot Tell Lies': Riddling and Ancient Greek Divination”. En Jan Kwapisz, David Petrain, y Mikołaj Szymański (eds), The Muse at Play. Riddles and Wordplay in Greek and Latin Poetry. Berlin: De Gruyter, pp. 121-147.

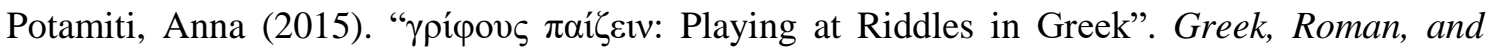
Byzantine Studies 55, pp. 133-153.

Pucci, Pietro (1996). Enigma, segreto, oracolo. Pisa-Roma: Istituti Editoriali e Poligrafici Internazionali.

Wehrli, Fritz (1948). Die Schule des Aristoteles. Texte und Kommentar. Heft III: Klearchos. Basel: Verlag. 